American J. of Engineering and Applied Sciences 3 (1): 73-82, 2010

ISSN 1941-7020

(C) 2010 Science Publications

\title{
Sustainability of Rainwater Harvesting Systems in Multistorey Residential Buildings
}

\author{
${ }^{1}$ A. Rahman, ${ }^{1} \mathrm{~J}$. Dbais and ${ }^{2}$ M. Imteaz \\ ${ }^{1}$ Department of Civil and Environmental Engineering, School of Engineering, University of Western \\ Sydney, Locked Bag 1797, Penrith South DC, NSW 1797, Australia \\ ${ }^{2}$ Department of Civil Engineering, Faculty of Engineering and Industrial Sciences, Mail H38, Swinburne \\ University of Technology, Hawthorn, Melbourne, VIC 3122, Australia
}

\begin{abstract}
Problem statement: The urban water supply systems in Australian large cities, which generally depend on large surface water reservoirs, are highly stressed due to rapid urban growth and severe drought conditions during the current decade. To ensure the long term sustainability of urban water supply, various alternative water sources including rainwater tanks, grey water, wastewater and desalination plants are being examined in Australia. In the previous research, it has been shown that rainwater tank of appropriate size, installed in detached small dwellings, can meet a significant proportion of household water demand, but there has been limited study on water savings and financial viability of Rain Water Harvesting System (RWHS) for multistorey residential buildings. This study examines the sustainability of RWHS in multistorey residential buildings in Sydney under different scenarios such as varying roof area, number of floors in the building, water price and interest rate to identify favorable condition where RWHS proves to be sustainable. Approach: A hypothetical multistorey building was considered and various scenarios in relation to site area and floor arrangement were established. A water balance model was developed to calculate water savings for various scenarios. Finally, life cycle costing was undertaken to identify most sustainable RWHS scenario for the hypothetical multistorey building. Results: It was found that a higher roof area is more favorable in terms of water savings and financial benefits. Capital and maintenance costs account for the majority of the expenditure of a RWHS. Plumbing cost forms the largest single component of the capital cost. It is shown that lower interest and increased water price regimes enhance the financial viability of RWHS. Conclusion: It was found that it is possible to achieve "pay back" for a RWHS under some favorable scenarios and conditions thus making the RWHS for multistorey buildings in Sydney sustainable.
\end{abstract}

Key words: Rainwater tanks, urban water cycle, life cycle costing, Australia, water sensitive urban design

\section{INTRODUCTION}

Australia is a highly urbanized country and perhaps the driest inhabited continent on earth with highly variable rainfall. For the last 10 years and so, Australia has been experiencing severe drought which has created significant water management problems. General public, media and political parties in Australia have been showing notable concern on declining water availability in Australia and undoubtedly 'water' has emerged as a national issue. Three major cities in Australia namely Sydney, Melbourne and Brisbane where about $50 \%$ of Australia's total population live have been experiencing mandatory water restrictions for the last 5 years and so. Water supply authorities in
Australia has been desperately looking for alternative sources of fresh water including rainwater tanks in addition to recycling grey water, wastewater and use of desalination plants.

Although a rainwater tank of appropriate size can meet a significant proportion of household water demand for small dwellings and quality of water from the tank is not a problem for non-potable uses, the financial viability of a rainwater harvesting system (RWHS) to individual house owner is yet to be established, in particular with the current water price in Australia. There is a general lack of research on long term sustainability of rainwater tanks, in particular for multistorey residential developments.

Corresponding Author: A. Rahman, School of Engineering, University of Western Sydney, Locked Bag 1797 , Penrith South DC, NSW 1797, Australia Tel: +61 247360145 Fax: +61 247360833 
Rainwater tanks can be traced back in Asia to about the 9th Century. In recent years, there has been notable research on rainwater tanks for small dwellings in Australia. For example, Coombes and Kuczera, (2003) evaluated the performance of 1-10 kL rainwater tanks for small dwellings in four Australian capital cities with mains water trickle top up used to supplement mains water supply for domestic toilet, laundry, hot water and outdoor usages. The results obtained from this study showed that the use of rainwater tanks resulted in considerable mains water savings in each city. Depending on roof area and number of occupants in the household, the use of rainwater tanks resulted in an annual mains water savings ranging from $18-55 \mathrm{~kL}$ for $1 \mathrm{~kL}$ rainwater tank and 25-144 kL for $10 \mathrm{~kL}$ rainwater tank.

Grant and Hallmann, (2003) undertook a life cycle assessment for rainwater tanks of 600 and $2250 \mathrm{~L}$ to estimate the economic benefits and costs of the tanks from the consumer's perspective. The total saving for the household water bill was estimated to be around $29.6 \%$ for the $2250 \mathrm{~L}$ tank. They found that neither one of the two tanks paid back within 30 years with the existing water price. Coombes and Kuczera, (2003) demonstrated that a particular mix of source control techniques making use of rainwater tanks can produce significant economic benefits to the community, whilst maintaining high public health standards and also produce significant gains for the ecosystems that underpin the urban water cycle. Coombes and Kuczera, (2003) investigated the economic benefit of traditional base scenario for urban water cycle services and alternative scenarios that include rainwater tanks. They found that the economic benefits derived from the use of rainwater tanks vary with the price of mains water and the cost to augment mains water supply headwork systems. Lower interest favored the RWHS.

Villarreal and Dixon, (2005) investigated the water savings potential of RWHS from large roof areas in Sweden. They found that $30 \%$ of mains water savings can be achieved from a $40 \mathrm{~m}^{3}$ tank if rainwater is used for toilet flushing and washing machine. Roebuck and Ashley, (2006) discussed the development of a computer based modeling and assessment tool for rainwater harvesting system intended for domestic, commercial, industrial and public buildings. They argued that many of the current methods of rainwater tank analysis overestimated the hydraulic efficiency and potential cost savings that are achievable with rainwater tanks. They estimated the life cycle costing of a fictitious school building with an estimated 65 years life cycle. The results were compared with the rainwater tank supplier's own assessment and it was discovered that the results obtained using their model were significantly different from those provided by the supplier. The expected long term savings were $£ 18,370$ over 65 years as opposed to $£ 122,230$ predicted by the supplier. The main factor of this discrepancy was the fact that interest rates were not considered by the supplier. The estimated payback period by the supplier was 10 years as opposed to 17 years by Roebuck and Ashley, (2006). A break down of the costs revealed that maintenance accounted for $26 \%$ of the total expenditure, capital costs contributed $31 \%$ and the mains top up comprised $40 \%$ of total expenditure. Mitchell and Rahman, (2006) found that RWHS is not financially viable for multistorey buildings in Sydney, Australia at the current water price. However, their cost estimate appears to be too conservative.

Ghisi et al. (2007) investigated the water savings potential from rainwater harvesting system in Brazil and found that average potential for potable water savings range from $12-79 \%$ year $^{-1}$ for the cities analyzed. Ideal rainwater tank sizes for dwellings with low potable water demand range from about 2-20 kL depending on rainwater demand. For dwellings with high potable water demand, ideal rainwater tank sizes range from about 3-7 $\mathrm{kL}$. The main conclusion drawn from the research was that the average potential for potable water savings in south-eastern Brazil is $41 \%$. They concluded that rainwater tank capacity has to be determined for each location and dwelling as it depends strongly on potable water and rainwater demand.

Most of the previous studies have found RWHS to be financially unrewarding under the current water price regime where water is supplied to urban residents at subsidized rate. This paper examines the sustainability of RWHS in a multistorey residential building in Sydney Australia to identify favorable condition where RWHS proves to be financially viable.

\section{MATERIALS AND METHODS}

In this study, a hypothetical multistorey building was considered, assumed to be located in the Botany Bay Council in Sydney, Australia. To examine various scenarios with RWHS two different site areas were considered: 2000 and $4000 \mathrm{~m}^{2}$ with roof areas of 800 and $1600 \mathrm{~m}^{2}$, respectively. For each of these two site areas, three different floor arrangements were considered assuming four apartments per floor and 3 persons per apartment: (a) Four floors with 16 apartments and 48 persons (b) 6 floors with 24 apartments and 72 persons (c) 8 floors with 32 apartments and 96 persons. Daily rainfall record over 60 years (January 1946 to December 2005) from Sydney Airport station was used to assess the performance of the RWHS. 
Am. J. Engg. \& Applied Sci., 3 (1): 73-82, 2010

Table 1: Estimated indoor water demand data

\begin{tabular}{lll}
\hline Activity & Frequency & Water demand \\
\hline Toilet flush (3A-rated dual flush) $(6 \mathrm{~L}$ full flush) & 3 equivalent full flush person day $^{-1}$ & $18 \mathrm{~L} \mathrm{person}^{-1} \mathrm{day}^{-1}$ \\
Toilet flush (other) (11 L full flush) & 3 equivalent full flush person $^{-1}$ day $^{-1}$ & $33 \mathrm{~L} \mathrm{person}^{-1} \mathrm{day}^{-1}$ \\
Washing machine (4A- or 5A-rated), 50 L load & 3 washes week & $50 \mathrm{~L} \mathrm{load}^{-1}$ \\
Washing machine (other), 153 L load & 3 washes week & $153 \mathrm{~L} \mathrm{load}^{-1}$ \\
\hline
\end{tabular}

Table 2: Irrigation frequency for lawns in various months of the year

\begin{tabular}{ll}
\hline Month & Frequency of irrigation \\
\hline Nov., Dec., Jan., Feb. and March & 2 times in 7 days \\
April and October & 1 time in 7 days \\
May, June, July, August and September & 1 time in 14 days \\
\hline
\end{tabular}

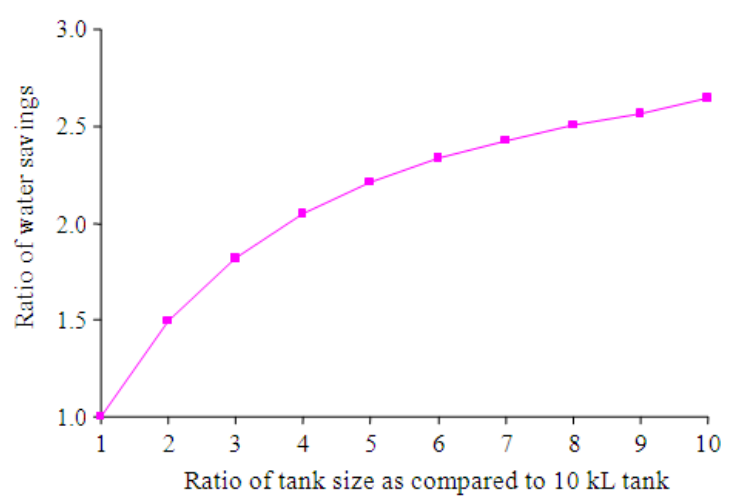

Fig. 1: Water savings of various tank sizes as compared to $10 \mathrm{~kL}$ tank size for a multistorey residential building in Sydney with site area of $4000 \mathrm{~m}^{2}$ and roof area of $1600 \mathrm{~m}^{2}$

Eroksuz et al. (2006) found that a rainwater tank of 70$80 \mathrm{~kL}$ size would possibly be the most appropriate size to meet majority of the water demand in a typical multistorey building in Sydney (Fig. 1) and hence a $75 \mathrm{~kL}$ tank size was selected for the purpose of this study.

The Building Sustainability Index (referred to as BASIX) for multi-unit buildings has been introduced by New South Wales Department of Planning, (2005). It is a web based tool that measures the potential performance of new residential dwellings against sustainability indices. BASIX requires all new houses to use up to $40 \%$ less potable water than the average one. This involves rainwater harvesting, use of various water efficient appliances in building such as 4A rated washing machine and dishwashers, $3 \mathrm{~A}$ rated dual flush toilets, shower heads and taps and native, low-wateruse landscaping. Both BASIX and non-BASIX (i.e., traditional) approaches with RWHS are examined in this study.

Water demand data: In this study, it was assumed that rainwater would be used for toilet flushing and laundry (indoor water use) and car washing and irrigation (outdoor water use). The relevant water demand data were obtained from Sydney Water (water supply authority in Sydney) as summarized in Table 1 for indoor water use. It was assumed that the indoor water demand would remain unaffected by seasonal variations and the household occupancy rate would not vary from month to month in a year. Of the total unbuilt area, $40 \%$ was assumed to be impervious and the remaining $60 \%$ landscaped (40\% garden area and $20 \%$ lawn area). The BASIX approach suggests the use of native and lowwater-use plants and lawns as opposed to the nonBASIX approach which typically includes non-native and less water-efficient plants. In BASIX approach, 10 $\mathrm{mm}$ irrigation once every week is considered to be adequate for native plants; however, for lawns $10 \mathrm{~mm}$ irrigation per application at varying frequencies (Table 2) depending on the month of the year is adopted. Sydney Water, (2006) further adds that mulching for plants can reduce evaporation by up to $70 \%$ thus reducing the required irrigation depth from 10 to $3 \mathrm{~mm} \mathrm{week}^{-1}$. In this study, mulching for plants was considered only for the BASIX approach. Application of fertilizer for the lawn as recommended in the BASIX approach was also considered in this study which could reduce water demand by up to $30 \%$ (Sydney Water, 2006). The car washing demand was taken to be $180 \mathrm{~L}_{\text {wash }}{ }^{-1}$ with the frequency of one wash every fortnight.

All the rainfall reaching a roof does not enter into rainwater tank due to losses arising from factors such as surface wetting, evaporation, ponding in depressions, leaks, surface splashing and first flush retention. It was assumed that $85 \%$ of the total rainfall falling on the roof would enter into the tank. First flush can be described as a proportion of roof runoff requiring separation to minimize pollutants such as dust and leaves from entering into the tank. Following the guideline of the local city council, first flush volumes of 800 and $1,600 \mathrm{~L}$ were considered for the 800 and $1600 \mathrm{~m}^{2}$ roof areas, respectively.

Life cycle costing data: The cost of rainwater tank and various accessories were obtained from local suppliers; price of an item was obtained from a number of local suppliers and the lowest price being selected. The capital cost represents the initial cost of installing the RWHS. 
Am. J. Engg. \& Applied Sci., 3 (1): 73-82, 2010

Table 3: Accessories for RWHS

\begin{tabular}{llll}
\hline & Number & Cost & Total \\
\hline Leaf eater & 4 & Aus $\$ 59.95$ & Aus\$239.80 \\
First flush & 1 & Aus\$39.95 & Aus $\$ 39.95$ \\
Tank top up & 1 & Aus $\$ 255.00$ & Aus\$255.00 \\
Tank screen & 2 & Aus $\$ 16.94$ & Aus $\$ 33.88$ \\
\hline & & Total & Aus $\$ 568.63$ \\
\hline
\end{tabular}

The $75 \mathrm{~kL}$ rainwater tank was assumed to comprise of three $25 \mathrm{~kL}$ rainwater tanks with a price of Aus $\$ 2,690$ for each tank. The total cost of the concrete base to support the tank was estimated to be Aus $\$ 567$ (assuming $20 \mathrm{MPa}$ concrete, slab thickness of $100 \mathrm{~mm}$ and diameter of $11.01 \mathrm{~m}$ ). Rainwater needs to be pumped from tank to upper floors for indoor use for which a vertical multi-stage pump was selected with following specifications: Davey V305 vertical multistage pressure system, flow rate $20 \mathrm{~L} \mathrm{~min}^{-1}, 0.75 \mathrm{~kW}$ motor and cost Aus $\$ 2,258$. The outdoor pump for irrigation should be capable of coping with the inconsistent pressure due to varying water level in the tank; in this study, the selected outdoor pump had following specifications: 2HM4-DS automatic horizontal multi-stage pressure system, system flow rate $20 \mathrm{~L} \mathrm{~min}^{-1}, 0.45 \mathrm{~kW}$ motor and cost Aus $\$ 632$.

Apart from tank and pumps, some additional components are required for the RWHS to enhance water quality and to facilitate mains top up. These accessories are fitted to the rainwater tank, downpipes and/or gutters. One such accessory is leaf eater which has a primary and a secondary screen, the former filters out leaves and debris while the latter filters out mosquitoes and vermin, if any. The leaf eater is self cleaning and requires little maintenance. It was assumed that there would be 4 downpipes from the roof which would require 4 leaf eaters (at a price of Aus $\$ 59.95$ per leaf eater). Only one first flush device is necessary and is installed beyond the point where the downpipes combine into one pipe section that leads to the tank. The cost of a first flush device was estimated to be Aus $\$ 39.95$.

A tank top up system facilitates a dual supply of water i.e., it ensures that there is a minimum supply of water in the tank. The system utilizes a valve that when activated introduces mains water to the tank. The tank top up automatically ceases once the water level reaches the designated minimum level which in this case was assumed to be of $20 \%$ of tank capacity. The cost of the tank top up system was estimated to be Aus $\$ 255$. Tank screens are generally fitted to all openings to and from the rainwater tank which provide the last line of defence in keeping pests out of the tank.
Table 4: Cost for downpipe

\begin{tabular}{lllll}
\hline Roof area $\left(\mathrm{m}^{2}\right)$ & Length $(\mathrm{m})$ & Diameter $(\mathrm{mm})$ & Cost $^{-1}$ & Total cost \\
\hline 800 & 120 & 100 & Aus $\$ 45.75$ & Aus $\$ 5,490$ \\
1600 & 200 & 100 & Aus $\$ 45.75$ & Aus $\$ 9,150$ \\
\hline
\end{tabular}

Table 5: Total plumbing cost for RWHS Roof area $\left(\mathrm{m}^{2}\right)$

\begin{tabular}{lll} 
Floors & 800 & 1,600 \\
\hline 4 & Aus $\$ 15,813.20$ & Aus $\$ 22,929.20$ \\
6 & Aus $\$ 19,806.80$ & Aus $\$ 28,458.80$ \\
8 & Aus $\$ 23,800.40$ & Aus $\$ 33,998.40$ \\
\hline
\end{tabular}

Two tank screens are required to be fitted, one for the tank inlet and the other for the overflow outlet; the cost of this device was estimated to be Aus $\$ 16.94$ per piece. Table 3 provides a summary of the required accessories and associated costs. The RWHS requires additional and larger down pipes and a separate internal reticulation system for the toilet and laundry. Downpipes are necessary to convey stormwater from the roof regardless of whether or not a rainwater tank is installed. There are, however, some additional costs as the downpipe has to divert the runoff to a single point. As a result, the diameter of the downpipe has to be larger than normal downpipes. The details of the downpipes are presented in Table 4.

The pipe system conveying the harvested rainwater to various appliances was assumed to run through the same service duct as the potable water pipe. Assuming floor height of $4 \mathrm{~m}$ and the appliances being located to the furthest point away from the service duct, a conservative cost estimate was made. Piping is also required to link the rainwater tank with the building and to each floor; an estimate was made for each scenario assuming $4 \mathrm{~m}$ of floor height, it was assumed that 20 $\mathrm{mm}$ diameter polyethylene pipe would be used having a price of Aus $\$ 19.20 \mathrm{~m}^{-1}$. It was estimated that it would take $16 \mathrm{~h}$ by a plumber (at a rate of Aus $\$ 55.00 \mathrm{~h}^{-1}$ ) to complete the additional works associated with the RWHS. The total plumbing costs including labor for each scenario are presented in the Table 5. It was estimated that it would take an electrician four hours to install the pumps (at a rate of Aus $\$ 50.00 \mathrm{~h}^{-1}$ ). Sydney Water offers a rebate for rainwater tanks with the amount depending on the size of the tank and whether or not it is plumbed into the toilet and washing machine. The RWHS considered in this study is eligible for an Aus $\$ 650$ rebate. The summary of the capital costs for the RWHS is presented in Table 6.

Maintenance and operating cost: Routine maintenance is required to ensure that the RWHS operates smoothly and the water quality remains acceptable. The general maintenance routine varies from site to site with some sites requiring more frequent maintenance due to causes such as overhanging trees. 
Am. J. Engg. \& Applied Sci., 3 (1): 73-82, 2010

Table 6: Summary of capital costs for RWHS

\begin{tabular}{ll}
\hline Item & Cost \\
\hline Rainwater tank & Aus $\$ 6,800.00$ \\
Concrete base & Aus $\$ 422.30$ \\
Pump (indoor) & Aus $\$ 2,258.30$ \\
Pump (outdoor) & Aus $\$ 632.50$ \\
Fittings & Aus $\$ 568.63$ \\
Plumbing cost + labor & As per Table 5 \\
Electrician & Aus $\$ 200.00$ \\
Sydney water rebate & Aus $\$ 650.00$ \\
\hline
\end{tabular}

Table 7: Summary of annual maintenance costs for RWHS

\begin{tabular}{llll}
\hline Item & Number year $^{-1}$ & Rate & Total \\
\hline Clean roof, gutters and inlets & 1.00 & Aus $\$ 85.00$ & Aus $\$ 212.50$ \\
Desludge tank & 0.33 & Aus $\$ 170.00$ & Aus $\$ 56.10$ \\
Pump maintenance (indoor) & 1.00 & Aus $\$ 112.92$ & Aus $\$ 112.92$ \\
Pump maintenance (outdoor) & 1.00 & Aus $\$ 31.63$ & Aus $\$ 31.63$ \\
\hline Total & & & Aus $\$ 413.14$ \\
\hline
\end{tabular}

The accessories with rainwater tanks are self-cleaning and therefore require little maintenance. It is generally advised that cleaning of roof, gutter, first flush device and inlets should be carried out on average once every six months. However, since this study deals with a multistory building which would unlikely have overhanging trees, it was assumed that once a year cleaning of various components of the RWHS would be adequate; it was assumed that it would take two persons three hours to perform this. Desluding of rainwater tanks are generally required once every 2 or 3 years. In this study, it was assumed that it would take two persons $1 \mathrm{~h}$ to desludge the three rainwater tanks once every 3 years. Annual pump maintenance cost was estimated to be $5 \%$ of the purchase price of the pump. The total maintenance costs for the RWHS are summarized in Table 7.

\section{Pump operation cost was estimated using following two equations:}

Pump running = Water demand (indoor or outdoor) $/$

time flow rate of pump

Pump operating $=$ Pump running time*motor power*cost cost of electricity*number of days year ${ }^{-1}$

It was assumed that the rainwater tank, accessories and the plumbing including the downpipes, with proper maintenance as indicated above would not require replacement during the life cycle of the RWHS. The pumps, however, would require replacement and it was assumed that the indoor pump would need to be replaced once every 10 years while the outdoor pump, which operates for less hours in a day than the indoor pump, would need replacement once every 15 years.
The life of the RWHS was assumed to be 60 years and the base year was taken to be 2006 i.e., in conducting the life cycle cost analysis, all the future costs associated with the RWHS such as maintenance and benefit were discounted to 2006 values. For this, three different discount rates were adopted: 5, 7.5 and $10 \%$. Inflation rate was used to estimate future cost of an item/service, although future prices of some items can increase in a rate faster than the inflation rate. The official inflation rate according to the Reserve Bank of Australia (2006) was $3.9 \%$ per annum as of September 2006, which was an unusually high figure driven by higher fuel cost and hence the inflation rate excluding volatile items of $2.6 \%$ per annum was adopted in this study. Due to the prolonged drought and the dwindling water supplies in Sydney, future water price is expected to rise at a rate higher than the current inflation rate and hence to estimate possible future water price, three different inflation rates were considered: 2.6, 3.5 and $4.5 \%$ per annum. This would provide an opportunity to see what water price would make a RWHS financially viable. The Goods and Services Tax (GST) of $10 \%$ was applied to the operating costs and to the cost of water as required by Australian government. The local electricity cost was 11.9215 cents $\mathrm{kwh}^{-1}$ as at September 2006 and the future price of electricity was assumed to rise with the rate of inflation of $2.6 \%$. The mains water price was obtained from Sydney Water, Aus $\$ 1.264 \mathrm{~kL}^{-1}$ for the first $100 \mathrm{~kL}$ per quarter and Aus $\$ 1.634 \mathrm{~kL}^{-1}$ for the excess amount.

Benefits of RWHS: The benefit of the RWHS is derived from the cost of water saved due to having a RWHS in the building. However, the current mains water price generally does not reflect the full cost of water because most of the water supply infrastructures/systems have been built by public money and water price is fixed at a lower value than the 'actual cost'. Also, the RWHS can offer other benefits such as households fitted with the RWHS would be less affected by water restrictions and would be able to water their gardens and wash the cars on most of the days of the week. Also, RWHS offers added security to urban water supply system on the events of unforeseen failure of urban water supply systems for factors such as eutrophication and bacterial pollution of water reservoirs and terrorist attack. Also installation of RWHS in majority of the households in a city would result in deferral of infrastructure such as dams which would have been required if RWHS was not adopted. However, it is difficult to estimate the cost of these benefits and hence was not considered in this study which had certainly disfavored the financial benefits of 
the RWHS. These factors need to be kept in mind in the interpretation of the outcomes of this study.

Method: A 'continuous simulation type' water balance model was developed on daily time steps, which calculated the inflow to and outflow from the rainwater tank based on the water demand and rainfall data on a given day. The water demand in this study was assumed to be consisting of toilet flushing, laundry, car washing and irrigation demands as mentioned before, of which irrigation demand was difficult to estimate. This was due to the fact that on the days of rainfall and possibly on a number of subsequent days after rainfall, irrigation demand would be smaller than normal days. In order to account for this, following approximate but simple procedures were adopted: (i) For 1 day of rainfall, there should be no irrigation during the day but irrigation would resume on the next day. (ii) For 1-7 days of consecutive rainfall, there should be no irrigation during the rainfall days plus none for the equal number of previous days of consecutive rainfall. (iii) For 8-21 days of consecutive rainfall, there should be no irrigation during the rainfall days plus no irrigation for the equal number of previous days of consecutive rainfall up to 7 days. The water demand today is then calculated by adding the indoor demand, car washing demand and the required irrigation (garden and lawn) demand for the day.

From the water balance model, following output values were estimated on a daily basis: (i) net rainfall entering into the tank (ii) water in the tank (ii) water demand (iii) mains top up and (iv) water savings. The mains top up is the amount of water needed to top up the rainwater tank to the specified minimum level. The water savings is simply the difference between the water usage and the mains top up required.

Life cycle costing is the process of assessing the cost of a product over its life cycle or portion thereof (ASNZS, 1999). Life cycle cost is the sum of acquisition cost and ownership cost of a product over its life cycle. All past, present and future cash flows identified in the life cycle costing are converted to present value dollars and are a function of discount rates. This study uses the concept of nominal cost (the expected price that will be paid when a cost is due to be paid, including estimated changes in price due to changes in efficiency, inflation/deflation, technology and the like) and nominal discount rate (the rate to use when converting nominal costs to discounted costs). To convert a nominal cost $\left(\mathrm{C}_{\mathrm{N}}\right)$ to discounted cost $\left(\mathrm{C}_{\mathrm{D}}\right)$, following equation is used (ASNZS, 1999):
$C_{D}=C_{N} \times\left(\frac{1}{\left(1+d_{n}\right)^{y}}\right)$

Where:

$\mathrm{d}_{\mathrm{n}}=$ The nominal discount rate per annum

$\mathrm{y}=$ The appropriate number of years

The base year for the life cycle costing was assumed to be 2006 .

\section{RESULTS}

Estimated water demand data for BASIX and non-BASIX approaches and for various scenarios are shown Table 8 and 9 which show that the indoor water demand increases with the number of floors and the outdoor water demand increases with the site area as expected. It can also be seen that there is also a large difference in water usage between the BASIX and non-BASIX approaches mainly due to water efficient internal appliances in BASIX approach which reduce water use. The differences in irrigation water demand between BASIX and non-BASIX are due the mulching and fertilizer effects which are applied to plants and lawns in BASIX approach only which reduces water demand. Although, the costs for mulching and fertilizer in the BASIX approach is an additional cost over the non-BASIX approach, which however was ignored in this study.

It was then examined whether the rainwater available from the tank can meet the demand on an annual basis (Fig. 2 and 3). Here the 'net water entering the tank' is the water which is available to meet the intended indoor and outdoor usages, which is referred to as 'rainwater availability'.

\begin{tabular}{|c|c|c|c|c|c|c|}
\hline \multirow{2}{*}{$\begin{array}{l}\text { Site area }\left(\mathrm{m}^{2}\right) \\
\text { Number of floors }\end{array}$} & \multicolumn{3}{|c|}{2,000} & \multicolumn{3}{|c|}{4,000} \\
\hline & 4 & 6 & 8 & 4 & 6 & 8 \\
\hline Toilet demand ( $\left.\mathrm{kL} \mathrm{day}^{-1}\right)$ & 0.86 & 1.30 & 1.73 & 0.86 & 1.30 & 1.73 \\
\hline Laundry demand $\left(\mathrm{kL} \mathrm{day}^{-1}\right)$ & 0.34 & 0.51 & 0.69 & 0.34 & 0.51 & 0.69 \\
\hline Plant demand ( $\left.\mathrm{kL} \mathrm{day}^{-1}\right)$ & 0.21 & 0.21 & 0.21 & 0.41 & 0.41 & 0.41 \\
\hline Lawn demand $\left(\mathrm{kL} \mathrm{day}^{-1}\right)$ & 0.31 & 0.31 & 0.31 & 0.62 & 0.62 & 0.62 \\
\hline Car washing demand $\left(\mathrm{kL} \mathrm{day}^{-1}\right)$ & 0.21 & 0.31 & 0.41 & 0.21 & 0.31 & 0.41 \\
\hline Total $\left(\mathrm{kL} \mathrm{day}^{-1}\right)$ & 1.93 & 2.64 & 3.35 & 1.93 & 2.64 & 3.35 \\
\hline
\end{tabular}

\begin{tabular}{|c|c|c|c|c|c|c|}
\hline \multirow{2}{*}{$\begin{array}{l}\text { Site area }\left(\mathrm{m}^{2}\right) \\
\text { Number of floors }\end{array}$} & \multicolumn{3}{|c|}{2,000} & \multicolumn{3}{|l|}{4,000} \\
\hline & 4 & 6 & 8 & 4 & 6 & 8 \\
\hline Toilet demand (kL day $\left.{ }^{-1}\right)$ & 1.58 & 2.38 & 3.17 & 1.58 & 2.38 & 3.17 \\
\hline Laundry demand $\left(\mathrm{kL} \mathrm{day}^{-1}\right)$ & 1.05 & 1.57 & 2.10 & 1.05 & 1.57 & 2.10 \\
\hline Plant demand $\left(\mathrm{kL} \mathrm{day}^{-1}\right)$ & 0.69 & 0.69 & 0.69 & 1.37 & 1.37 & 1.37 \\
\hline Lawn demand ( $\left.\mathrm{kL} \mathrm{day}^{-1}\right)$ & 0.45 & 0.45 & 0.45 & 0.89 & 0.89 & 0.89 \\
\hline Car washing demand $\left(\mathrm{kL} \mathrm{day}^{-1}\right)$ & 0.21 & 0.31 & 0.41 & 0.21 & 0.31 & 0.41 \\
\hline Total $\left(\mathrm{kL} \mathrm{day}^{-1}\right)$ & 3.98 & 5.40 & 6.82 & 3.98 & 5.40 & 6.82 \\
\hline
\end{tabular}


Am. J. Engg. \& Applied Sci., 3 (1): 73-82, 2010

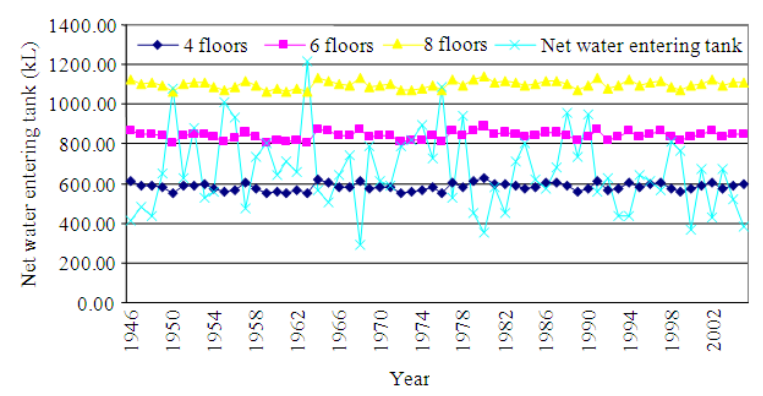

Fig. 2: Water availability in rainwater tank Vs water demand (BASIX and 2,000 $\mathrm{m}^{2}$ site area)

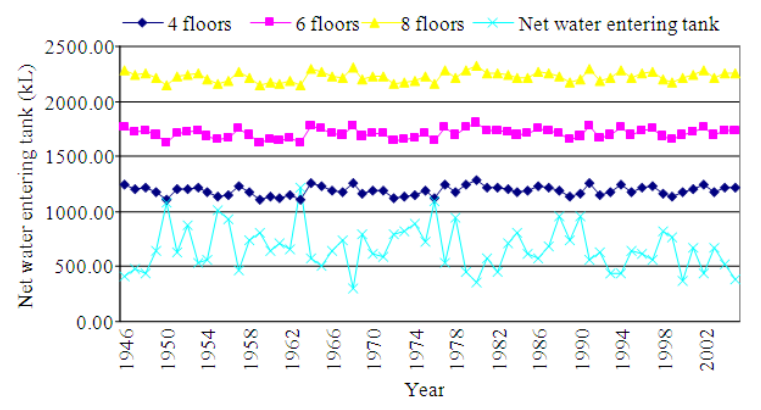

Fig. 3: Water availability in rainwater tank Vs water demand (Non-BASIX and 2,000 $\mathrm{m}^{2}$ site area)

It can be seen in Fig. 2 that for the 4 floor BASIX building with $2,000 \mathrm{~m}^{2}$ site area annual rainwater availability exceeds the annual water demand for more than $50 \%$ of the years during the period of modeling of 60 years. It however does not mean that the mains top up is not required for the years where the annual rainwater availability exceeds the annual water demand since all the rainwater entering into the tank cannot be utilized in many cases due to overflow from the tank which is likely to happen during most intense rainfall events. For the 6 floor building, the 'water availability' exceeds the annual water demand for only a few times during the 60 years period and for the 8 floor building this happens only once. These mean that in general mains top up would increase with increasing floor numbers. For Non-BASIX approach, it can be seen from Fig. 3 that the annual water availability exceeds the water demand only once for the 4 floor scenario and none for the 6 floor and 8 floor scenarios.

It can be seen in Fig. 4 that with the larger area (site area $4,000 \mathrm{~m}^{2}$ and roof area $1600 \mathrm{~m}^{2}$ ), the 'water availability' far exceeds the water demand for the majority of the years for the 4 and 6 floor scenarios. In fact, the 'water availability' exceeds the water demand for 58, 48 and 32 years out of 60 years for the 4 floor, 6 floor and 8 floor cases, respectively.

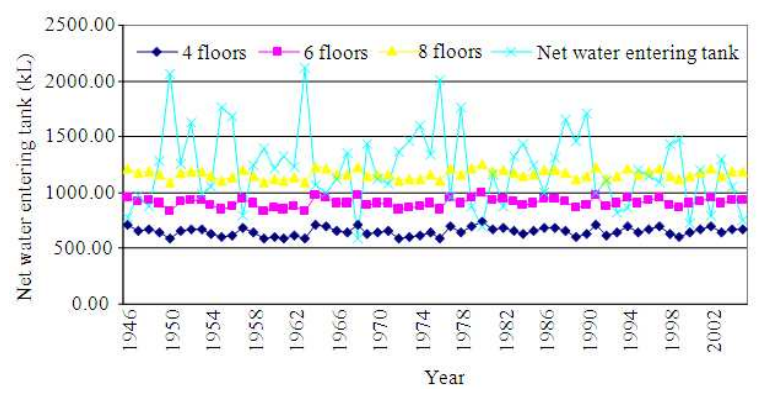

Fig. 4: Water availability in rainwater tank Vs water demand (BASIX and 4,000 $\mathrm{m}^{2}$ site area)

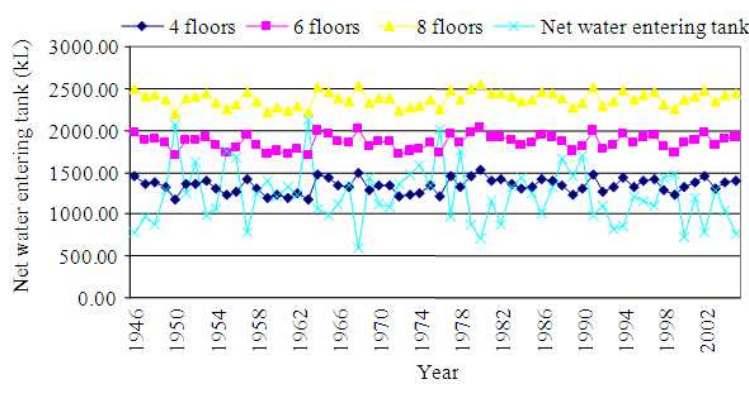

Fig. 5: Water availability in rainwater tank Vs water demand (Non-BASIX and 4,000 $\mathrm{m}^{2}$ site area)

Table 10: Average annual mains top up required $(\mathrm{kL})$ and percentage increase as compared to 4 floor case

\begin{tabular}{|c|c|c|c|c|}
\hline \multirow[b]{2}{*}{ Scenario } & \multirow{2}{*}{$\begin{array}{l}\text { Site } \\
\text { area }\left(\mathrm{km}^{2}\right)\end{array}$} & \multicolumn{3}{|c|}{ Number of floors } \\
\hline & & 4 & 6 & 8 \\
\hline \multirow[t]{2}{*}{ BASIX } & 2,000 & 136 & $329(141 \%)$ & $553(306 \%)$ \\
\hline & 4,000 & 94 & $229(143 \%)$ & $402(327 \%)$ \\
\hline \multirow[t]{2}{*}{ Non-BASIX } & 2,000 & 641 & $1126(75 \%)$ & $1626(153 \%)$ \\
\hline & 4,000 & 565 & $986(74 \%)$ & $1441(155 \%)$ \\
\hline
\end{tabular}

These show the advantage of having a larger roof area which can catch greater rainfall volume than a smaller roof area. Fig. 5 shows that as the water demand increases with the non-BASIX approach, the 'water availability' is unable to meet the annual demand. Despite the larger roof area, the 'water availability' exceeds annual demand for only 18, 2 and 0 times for 4, 6 and 8 floors cases. These results show that in BASIX approach, RWHS can provide water more reliably over the years than the non-BASIX approach in particular for larger roof areas.

The annual average mains top up over the 60 years period is shown in Table 10 which show that the mains top up volume increases with increased floor numbers with the 8 floor case requiring significantly greater mains top up volume than the 4 and 6 floor cases. Generally, 6 and 8 floor cases require 2-4 times higher top up volumes than the 4 floor case. 
Am. J. Engg. \& Applied Sci., 3 (1): 73-82, 2010

Table 11: Average annual water savings per year $(\mathrm{kL})$

\begin{tabular}{lllll}
\hline & & \multicolumn{3}{l}{ Number of floors } \\
& & - & \\
Scenario & Site area $\left(\mathrm{km}^{2}\right)$ & 4 & 6 & 8 \\
\hline BASIX & 2,000 & 446 & 511 & 545 \\
& 4,000 & 554 & 678 & 762 \\
\multirow{2}{*}{ Non-BASIX } & 2,000 & 546 & 579 & 598 \\
& 4,000 & 773 & 870 & 934 \\
\hline
\end{tabular}

Table 12: Capital costs of RWHS for different scenarios Number of floors

\begin{tabular}{llll} 
Site area $\left(\mathrm{km}^{2}\right)$ & 4 & 6 & 8 \\
\hline 2,000 & Aus $\$ 27,459$ & Aus $\$ 31,453$ & Aus $\$ 35,446$ \\
4,000 & Aus $\$ 34,575$ & Aus $\$ 40,105$ & Aus $\$ 45,634$ \\
\hline
\end{tabular}

Table 13: Pump operation cost for each scenario (Aus\$)

\begin{tabular}{lllll}
\hline & \multicolumn{4}{l}{ Number of floors } \\
\cline { 3 - 5 } Scenario & Site area $\left(\mathrm{km}^{2}\right)$ & 4 & 6 & 8 \\
\hline BASIX & 2,000 & Aus\$5,169 & Aus\$7,534 & Aus\$9,899 \\
\multirow{2}{*}{ Non-BASIX } & 4,000 & Aus\$5,609 & Aus\$7,974 & Aus $\$ 10,339$ \\
& 2,000 & Aus $\$ 11,312$ & Aus\$16,472 & Aus $\$ 21,632$ \\
& 4,000 & Aus $\$ 12,304$ & Aus $\$ 17,464$ & Aus $\$ 22,624$ \\
\hline
\end{tabular}

There is also a significant increase in the mains top up volume (by about 3-6 folds) for the non-BASIX approach over the BASIX one. It is also noted that the mains top up volume decreases with increasing roof area e.g., approximately 40 and $15 \%$ decrease for BASIX and non-BASIX approaches respectively.

Table 11 compares the average annual water savings for various cases which shows an increase in water savings with increasing floor numbers. The water savings also increase with an increased roof area. It can also be seen from Table 11 that the maximum water savings occur with the non-BASIX approach for the 8 floor case with a $4,000 \mathrm{~m}^{2}$ site area. It is this scenario that is likely be the most viable option although the increased plumbing costs of the additional floors might offset the additional savings gained, which is investigated in the following section.

It can be seen from Table 12 that the capital cost for the RWHS increases with the larger roof area and with the number of floors, which is due to the additional length of downpipes for the larger building and an increased plumbing cost. The capital costs were assumed to be the same for the BASIX and non-BASIX approaches. Table 13 shows that the pump operating cost increases when the water demand is higher i.e., with increased floor number and larger site area. The most significant increases occur between the BASIX and non-BASIX approaches where pump operation cost for the non-BASIX approach is about twice than the BASIX one.

Benefit cost ratio (the ratio of total discounted benefit over total discounted cost of the RWHS over the 60 years life cycle) was obtained for all the cases.

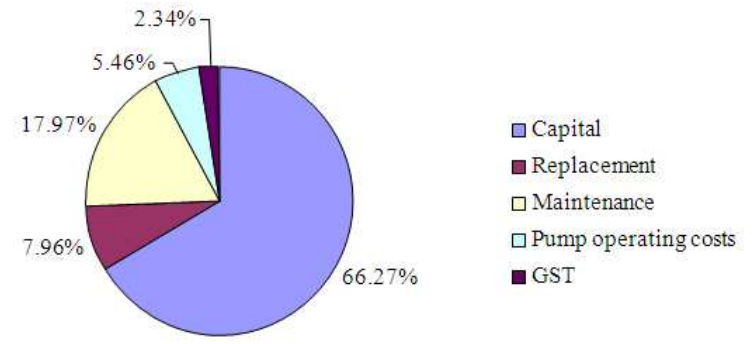

Fig. 6: Breakdowns of whole life cycle costs

Table 14 and 15 present the results for two cases: (a) water price Aus $\$ 1.264 \mathrm{~kL}^{-1}$ and current inflation of $2.6 \%$ p.a. considered for all items including water price, which shows benefit/cost ratios in the range of 0.17-0.68 i.e., RWHS does not pay back in 60 years project life and (b) water price of Aus $\$ 1.634 \mathrm{~kL}^{-1}$, $2.6 \%$ inflation rate for all items except water price (4.5\% inflation rate was considered for water price) which produces benefit/cost ratio in the range of 0.44 and 1.39 . At $5 \%$ nominal discount rate, RWHS shows a benefit that is greater than the associated costs. From the analysis, it was revealed that the most viable option was the 4 floor case using a non-BASIX approach with a site area of $4,000 \mathrm{~m}^{2}$ which gives a benefit/cost ratio of 1.39. For this scenario, the payback period occurred on the 38th year i.e., there would be real savings from 39th-60th year.

The $2,000 \mathrm{~m}^{2}$ site area had a lower benefit/cost ratio than the $4,000 \mathrm{~m}^{2}$ site area. In some cases, the benefit/cost ratio decreased with the number of floors somewhat offsetting the increased water savings obtained for the 6 and 8 floor buildings; the decrease in the benefit/cost ratio was a result of the increased plumbing cost associated with the 6 and 8 floor buildings. The benefit/cost ratio was smaller with the BASIX approach making the RWHS more financially viable in water hungry or non-BASIX compliant complexes.

A break down of the different cost components for the most favorable scenario is presented in Fig. 6. It can be seen that the capital costs comprise the highest component with $66 \%$ whereas the maintenance costs are the second highest contributing $18 \%$. The pump operating costs only contribute $5 \%$ of the total cost although when added to the pump capital, replacement and maintenance costs, the pump related expenditure rises to Aus $\$ 9,872$ or $19 \%$ of the total life cycle cost.

A further breakdown of the capital costs are presented in Fig. 7. It can be seen that the plumbing costs make up $66 \%$ of the total capital cost. 
Am. J. Engg. \& Applied Sci., 3 (1): 73-82, 2010

Table 14: Benefit/cost ratios at water price Aus $\$ 1.264 \mathrm{~kL}^{-1}$ and inflation rate of $2.6 \%$ p.a. for all items including water price Site area

Number of floors

\begin{tabular}{|c|c|c|c|c|c|c|c|}
\hline & & \multirow{2}{*}{\multicolumn{3}{|c|}{$2000 \mathrm{~m}^{2}$}} & \multirow{2}{*}{\multicolumn{3}{|c|}{$4000 \mathrm{~m}^{2}$}} \\
\hline & & & & & & & \\
\hline & Discount rate $(\%)$ & 4 & 6 & 8 & 4 & 6 & 8 \\
\hline \multirow[t]{3}{*}{ BASIX } & 5.0 & 0.47 & 0.49 & 0.48 & 0.50 & 0.55 & 0.55 \\
\hline & 7.5 & 0.34 & 0.35 & 0.34 & 0.35 & 0.38 & 0.39 \\
\hline & 10.0 & 0.26 & 0.27 & 0.26 & 0.27 & 0.29 & 0.29 \\
\hline \multirow[t]{3}{*}{ Non-BASIX } & 5.0 & 0.56 & 0.53 & 0.50 & 0.68 & 0.68 & 0.65 \\
\hline & 7.5 & 0.41 & 0.39 & 0.36 & 0.49 & 0.48 & 0.46 \\
\hline & 10.0 & 0.32 & 0.30 & 0.28 & 0.37 & 0.36 & 0.35 \\
\hline
\end{tabular}

Table 15: Benefit/cost ratios at water price Aus $\$ 1.634 \mathrm{~kL}^{-1}$ and inflation rate of $2.6 \%$ pa for all items (inflation rate for water price: $4.5 \%$ pa)

\begin{tabular}{|c|c|c|c|c|c|c|c|}
\hline & \multirow[b]{4}{*}{ Discount rate $(\%)$} & \multicolumn{6}{|c|}{ Site area } \\
\hline & & \multicolumn{6}{|c|}{ Number of floors } \\
\hline & & \multicolumn{3}{|c|}{$2000 \mathrm{~m}^{2}$} & \multicolumn{3}{|c|}{$4000 \mathrm{~m}^{2}$} \\
\hline & & 4 & 6 & 8 & 4 & 6 & 8 \\
\hline \multirow[t]{3}{*}{$\overline{\text { BASIX }}$} & 5.0 & 0.97 & 1.00 & 0.98 & 1.03 & 1.12 & 1.15 \\
\hline & 7.5 & 0.63 & 0.65 & 0.63 & 0.65 & 0.70 & 0.71 \\
\hline & 10.0 & 0.44 & 0.45 & 0.44 & 0.45 & 0.49 & 0.49 \\
\hline \multirow[t]{3}{*}{ Non-BASIX } & 5.0 & 1.15 & 1.09 & 1.02 & 1.39 & 1.38 & 1.33 \\
\hline & 7.5 & 0.76 & 0.71 & 0.67 & 0.89 & 0.88 & 0.85 \\
\hline & 10.0 & 0.54 & 0.51 & 0.47 & 0.63 & 0.62 & 0.59 \\
\hline
\end{tabular}

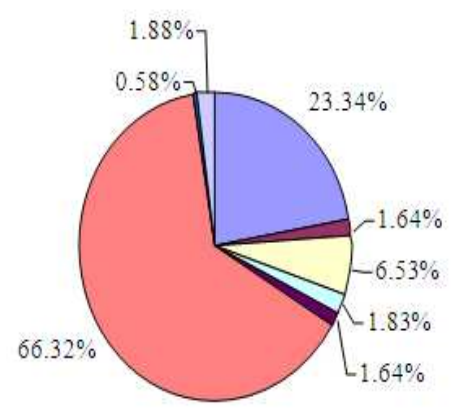

$\square$ Rainwater tank
$\square$ Concrete base
$\square$ Pump (indoor)
$\square$ Pump (outdoor)
$\square$ Accessories
$\square$ Plumbing cost-labor
$\square$ Electrician
$\square$ Sydney water rebate

Fig. 7: Breakdowns of capital costs

The rainwater tank itself forms a total of $23 \%$ of the capital cost component. The total capital costs for this scenario is Aus $\$ 34,575$ spread over 16 units which translate to just Aus $\$ 2,160$ unit $^{-1}$. This additional cost forms a small percentage of the total purchase price of the unit although it is unlikely to produce a payback for each individual unit owner.

\section{CONCLUSION}

This study examined the performances and financial viability of a $75 \mathrm{~kL}$ rainwater tank under various scenarios for a fictitious multistorey building in
Sydney. Following conclusions can be deduced from this study:

- It is possible to achieve "pay back" for a rainwater harvesting system under some favorable scenarios and conditions. The most favorable financial condition for the rainwater harvesting system among various scenarios examined here is $1600 \mathrm{~m}^{2}$ roof area, 5\% nominal discount rate, Aus $\$ 1.634 \mathrm{~kL}^{-1}$ water price and inflation rate of $4.5 \%$ p.a. for water price which presents a benefit/cost ratio of 1.39

- The benefit/cost ratio is smaller with the BASIX approach as compared to non-BASIX one. However, the overall water demand for the nonBASIX approach is much higher

- A higher roof and site area is more favorable than smaller ones in terms of water savings and financial benefit

- Capital and maintenance costs account for the majority of the expenditure over the whole life cycle cost of a rainwater harvesting system. Plumbing cost forms the largest single component of the capital cost. Cost related to pump maintenance and replacement forms a significant component of the total expenditure

- Rainwater tank harvesting system cannot be financially viable when rainwater is utilized less. In 
other words, to maximize the benefit, rainwater needs to be used as much as possible from the tank on a regular basis so that the tank is empty at the beginning of the next rainfall event

- At the current water price and high interest rate regimes, rainwater harvesting system is not financially profitable to individual flat owners which suggest that the current level of subsidy provided by the Australian government for rainwater harvesting system for multistorey buildings should be increased to reduce burden of the households and to enhance the sustainability of rainwater harvesting system

The findings of this study are subject to various assumptions on prices, frequency of maintenance works, assumed discount rates, tank size, site area and the like. Also, it should be noted here that rainwater harvesting system can provide many additional benefits such as added security to central water supply system, greener life style as less impact on residents from mandatory water restrictions, smaller urban runoff/ pollutant wash off and possible deferral of building major water supply infrastructures. These benefits were not included in this study due to the unavailability of relevant data, which would have favored the rainwater harvesting system.

\section{ACKNOWLEDGEMENT}

The researchers would like to acknowledge Mr. Caleb Mitchell, Mr. Erhan Eroksuz, Dr. Phil Ronaldson and Dr. Surendra Shrestha, University of Western Sydney for their suggestions and inputs to this study.

\section{REFERENCES}

Australian/New Zealand Standard (ASNZS), 1999. Life cycle costing- an application guide. Standards Australia, ISBN: 073372507 4, pp: 7.

Coombes, P.J. and G. Kuczera, 2003. A sensitivity analysis of an investment model used to determine the economic benefits of rainwater tanks. Proceeding of the 28th Hydrology and Water Resources Symposium, Nov. 10-14, Engineers Australia, Wollongong, Sydney, pp: 243-250.

Coombes, P.J. and G. Kuczera, 2003. Analysis of the performance of rainwater tanks in Australian capital cities. Proceeding of the 28th Hydrology and Water Resources Symposium, Nov. 10-14, Engineers Australia, Wollongong, Sydney, pp: 235-242.
Eroksuz, E., A. Rahman and M. Jeffery, 2006. Economics of rainwater tanks in multistorey complexes in three cities of New South Wales Australia. Proceeding of the 4th International Conference on Water Sensitive Urban Design, Apr. 3-7, Melbourne, Australia, pp: 715-722.

Ghisi, E., D.L. Bressan and M. Martini, 2007. Rainwater tank capacity and potential for potable water savings by using rainwater in the residential sector of southeastern Brazil. Build. Environ., 42: $\quad 1654-1666 . \quad$ DOI: 10.1016/j.buildenv.2006.02.007

Grant, T. and M. Hallmann, 2003. Urban domestic water tanks: Life cycle assessment. Water, 30: 3641. http://www.awa.asn.au/

Mitchell, C. and A. Rahman, 2006. Life cycle cost analysis of rainwater tank in a multistorey residential building in Sydney. Proceedings of the 30th Hydrology and Water Resources Symposium, Dec. 4-7, Launceston, Australia, pp: 1-6.

New South Wales Department of Planning (NSWDP), 2005. The Building Sustainability Index (BASIX), NSW Govt., Australia. http://www.basix.nsw.gov.au/information/index.jsp

Roebuck, R.M. and R.M. Ashley, 2006. Predicting the hydraulic and life-cycle cost performance of rainwater harvesting systems using a computer based modeling tool. Proceeding of the 4th International Conference on Water Sensitive Urban Design, Apr. 2-7, Melbourne, Australia, pp: 699-706.

Sydney Water, 2006. Water usage charge. Sydney Water, Australia. http://www.sydneywater.com.au/

Villarreal, E.L. and A. Dixon, 2005. Analysis of a rainwater collection system for domestic water supply in Ringdansen, Norrkoping, Sweden. Build. Environ., 40: 1174-1184. DOI: 10.1016/j.buildenv.2004.10.018 